\title{
Group Size and Conformity
}

\author{
Rod Bond \\ University of Sussex
}

\begin{abstract}
This paper reviews theory and research on the relationship between group size and conformity and presents a meta-analysis of 125 Asch-type conformity studies. It questions the assumption of a single function made in formal models of social influence and proposes instead that the function will vary depending on which social influence process predominates. It is argued that normative influence is likely to be stronger when participants make public responses and are face-to-face with the majority, whereas informational influence is likely to be stronger when participants make private responses and communicate with the majority indirectly. The meta-analysis finds that the relationship differs according to whether public or private responses are obtained and whether an Asch or Crutchfield paradigm is employed. Future research needs to identify how the relationship varies depending on different social influence processes elicited by features of the task and setting.
\end{abstract}

KEYWORDS conformity, meta-analysis, social-influence

ONE of the oldest questions in social influence research concerns the relationship between conformity and the size of the majority. Asch's (1951, 1955) startling conclusion that majority size did not have much effect beyond a minimal number provoked a lively debate, one that continues to be presented in almost every textbook on social psychology. More recent theories, such as Latané's (1981) Social Impact Theory (SIT), mostly disagree with Asch and hold that the larger the size of the majority, the larger the effect, and the main issue that currently distinguishes different models is the precise form that the relationship of group size to conformity is supposed to take.

In contrast, this paper questions the dominant assumption that there will be a single function that describes the relationship. Instead, it argues that a number of social influence processes give rise to conformity and that the function will depend on which process predominates, depending on particular features of the task and setting.

There are three main parts to this review. The first compares theories of group size and conformity in terms of the form of the relationship proposed and the social influence process presumed to give rise to it. The second part is a narrative review of the existing empirical evidence for the relationship, including both individual studies and previous meta-analytic reviews, and finds that existing evidence is

\section{Author's note}

Address correspondence to Rod Bond, Department of Psychology, University of Sussex, Brighton BN1 9QH, UK [email: r.bond@sussex.ac.uk] 
inconclusive. The third part presents a new meta-analysis that investigates whether the relationship varies depending on two features of the task and setting: whether the experimental paradigm entails the participant in faceto-face or indirect interaction with the majority and whether the participant gives a public or private response. Only studies which use Asch's (1952a, 1956) line judgment task and where a unanimous majority confronts a single individual were selected, thereby exercising greater control than previous meta-analyses, especially over differences between studies that may be confounded with majority size. The aim is to demonstrate that the relationship between conformity and majority size is complex, in that it cannot be described by a simple function but instead varies systematically with factors that impact on social influence processes.

\section{Theories of group size and conformity}

Theories of group size and conformity have been concerned primarily with describing the functional relationship between these variables, rather than with how group size relates to the psychological processes involved in social influence. Nevertheless, the theories differ in their account of the psychological processes that mediate the relationship, as well as in the form of the relationship itself. Most theories draw on dual process theory, according to which conformity is explained by two distinct processes, one being normative influence, which reflects the group's power to reward and punish, and the other being informational influence, which reflects the group's capacity to provide information about reality (Deutsch \& Gerard, 1955). Whereas theories of group size and conformity have argued that these processes result in a single form of relationship, we shall argue in contrast that the form of relationship will depend on the relative strength of each of these motives.

Asch (1951, 1955, 1956) recognizes that the processes underlying response to group pressure are complex, and his analysis focuses on individual differences in response to group pressure in which normative and informational influence are involved to differing degrees. Nevertheless, his emphasis is on informational influence in that, for conformity to occur, the majority must provide an alternative, and apparently incontrovertible, version of reality which most participants decide is correct, or possibly correct. It is essential, therefore, for the majority to be unanimous (Asch, 1955), and of sufficient size that their judgments cannot be dismissed as idiosyncratic:

The majority, although limited in size, was representative. The minority individual had no reason to suppose that others, not included in the group, would be more likely to side with him. The given majority was symbolic of what any portion of humanity might perceive. (Asch, 1956, p. 67)

Increasing the size of the majority will have no additional impact, since the addition of further individuals who state the same view merely confirms that this is a representative sample. Asch concluded that a majority size of three is sufficient for the full impact of the group to be felt (Asch, 1955).

More recent theories, ${ }^{1}$ however, attach greater importance to group size and see both normative and informational influence as contributing to the effect. In SIT (Latané, 1981; Latané \& Wolf, 1981), it is argued that the larger the group the greater its impact, not just because the majority provide information about reality but also because of the majority's power to reward and punish. The relationship between group size and impact is not expected to be linear, however, and Latané (1981) proposes that the additional impact is smaller for each additional group member, so that the function relating group size to conformity is a negatively accelerating curve. This is expressed in the equation

$$
I=s N^{\mathrm{t}}
$$

where $I$ is impact, $s$ is a scaling constant, $N$ is the number of sources of influence, and the exponent $t$ is a value less than one. The theory also proposes that impact is a multiplicative function of the strength and immediacy of the 
influence sources, as well as number, and hence the steepness of the function will reflect features of the task and setting which affect these parameters, features which may also reflect whether normative or informational influence predominates. Latané and Wolf (1981) demonstrate that SIT provides a good fit to the results from two studies concerned with conformity and majority size, one by Gerard, Wilhelmy, and Conolley (1968) and another by Latané and Davis (cited in Latané \& Wolf, 1981).

Tanford and Penrod (1984), on the other hand, propose a Social Influence Model (SIM) entailing an S-shaped function relating group size and social influence. When the number of targets is a minority of one, the equation is

$$
I=\exp \left(-4 \times \exp \left(-\mathrm{N}^{1.75}\right)\right)
$$

where $I=$ impact, and $N=$ number of sources of influence. ${ }^{2}$ They argue that this is superior to SIT in two respects. First, whereas SIT predicts that the first influence source will have the greatest impact, Asch (1951) found that the second and third sources had greater additional impact than the first source. SIM is consistent with these results. Second, SIT proposes that additional group members will always have additional impact and therefore proposes, implausibly in Tanford and Penrod's view, that there is no limit to the amount of influence that a group may exert. SIM, on the other hand, allows for an asymptotic value so that group size is important only up to some limit beyond which increasing group size has no additional impact. Tanford and Penrod (1984) conducted a meta-analysis of conformity studies and found that SIM described very well the relationship between conformity and majority size, and better than did SIT.

A fourth theory proposed by Mullen (1983, 1987) explains the effect of group size on conformity in terms of self-attention theory (Carver, 1979; Carver \& Scheier, 1981), which holds that the more attention is focused on the self, the more people will attempt to match their behavior to salient behavioral standards. Where this is the majority norm, greater self-attention will result in greater conformity. Mullen argues that increasing majority size will lead to greater self-attention, since the minority individual will increasingly stand out as the figure against the ground provided by the majority, and hence increasingly feel the focus of attention. The Other-Total Ratio (OTR), the number in the 'other subgroup' (i.e. the majority in conformity studies) divided by the total number in the group, quantifies the degree of self-attention. Where the minority is a single individual, this can be expressed by the formula

$$
I=\alpha\left(\frac{N}{N+1}\right)
$$

where $I=$ impact, $\alpha$ is an influence constant which might vary from task to task, and $N=$ the size of the majority.

By applying OTR, Mullen proposes that the degree of self-attention, and hence conformity, will be a negatively accelerating function of group size. He argues that his model is superior to SIT in that the function is specified a priori, and a psychological process, self-attention, is proposed to explain the effect. In a metaanalysis, Mullen (1983) found that OTR described well the relationship between conformity and group size, and better than SIT.

Finally, Stasser and Davis (1981) propose, independently from Mullen (1983), that the relationship between conformity and group size can be described by the OTR, although their focus is on normative and informational influence rather than on self-attention, and their concern is with opinion change in small group discussion, rather than with studies in conformity. They focus on two functions of proportional size. The first, the inform influence function, is when the process is primarily one of informational influence. Influence will be directly related to the number expressing a particular view relative to the overall size of the group. When the process also involves normative influence, however, a two-stage sequential process is assumed described by the norm influence function. The first stage concerns the process of receiving the message and the second stage the process of yielding to it, and it 
is assumed that each stage is a function of proportional support. The greater the proportion of group members advocating a particular view, the more likely an individual is to receive those arguments and the more likely also that he or she will yield to it. Hence, opinion change will be a function of proportional support, or the OTR, squared. For a minority of one, their formula is

$$
I=\alpha\left(\frac{N}{N+1}\right)^{c}
$$

where $I=$ impact, $\alpha$ is an influence constant which might vary from task to task, and $N$ is the size of the majority. The inform influence function is when $c=1$, and the norm influence function is when $c=2$. Stasser and Davis (1981) also suggest that changes in the confidence with which an opinion is held privately is primarily a function of informational influence, and hence governed by the inform influence function, whereas publicly expressed opinion change is a function of both normative and informational influence, and hence governed by the norm influence function. Unlike the other theories, then, they propose that the form of the relationship between group size and conformity will vary, depending on whether the response is publicly or privately expressed. This will be explored further in this review.

The theoretical relationships between group size and conformity proposed by these different theories are compared in Figure 1, where the scaling constants have been selected to give similar predictions for a majority size of 3 . There are two main areas of disagreement. First, there is disagreement over the form of the function between none and three influence sources. SIT, OTR and the Norm Influence Function all specify negatively accelerated curves; SIM and Asch's (1951) results indicate an S-shaped function. Second, there is the question of whether influence reaches an asymptotic value. SIT, the OTR and the Norm Influence Function do not specify an asymptotic value whereas SIM and Asch do. SIT predicts the steepest rise in influence, followed

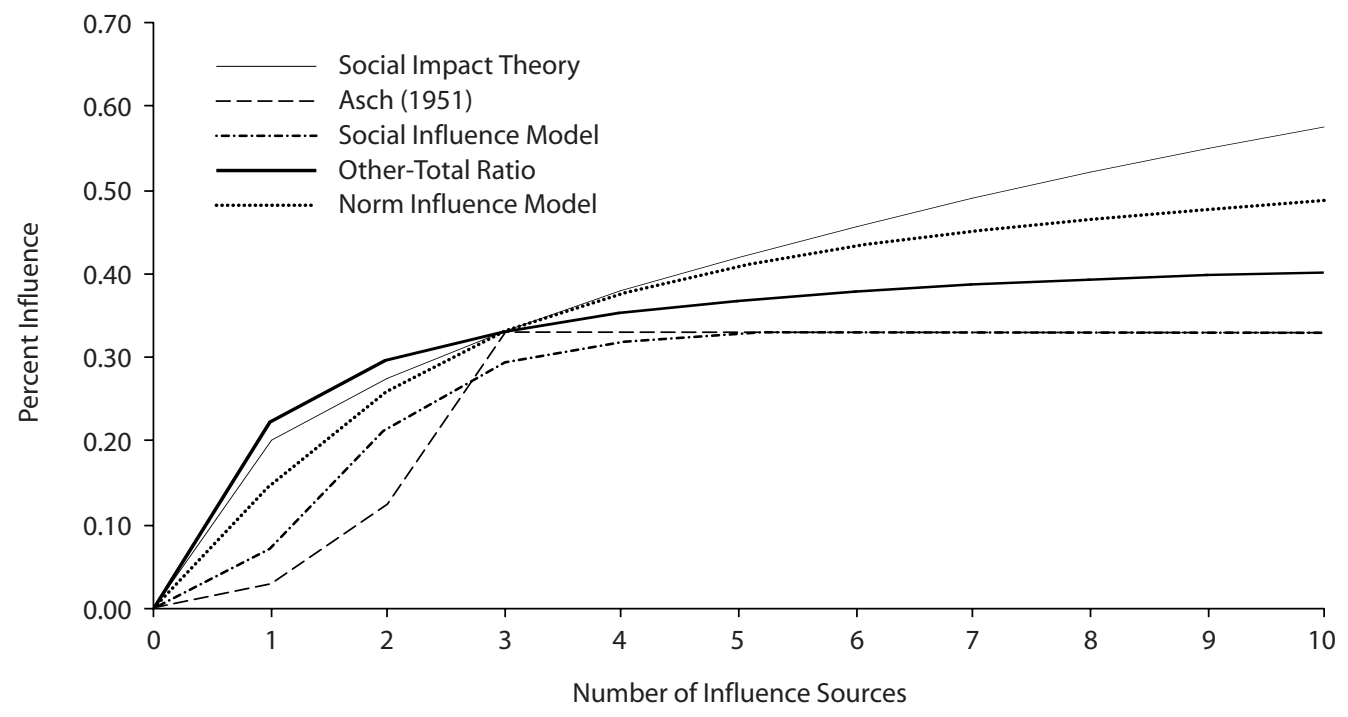

Figure 1. Theoretical relationships between group size and conformity.

Note: Social Impact Theory, $I=20 \mathrm{~N}^{0.46}$; Social Influence Model, $I=0.33 \times \exp \left(-4 \times \exp \left(-\mathrm{N}^{1.175}\right)\right)$;

Other-Total Ratio, $I=0.44(N /(N+1))$; Norm Influence Model, $I=0.59\left(N /(N+1)^{2}\right.$; where in each equation $I=$ percent influence, $N=$ number of influence sources. 
by the Norm Influence Model, followed by OTR.

Differences between the theories are subtle, however, with the consequence that they will be difficult to distinguish empirically. Moreover, the curvilinear form of the relationship is pronounced mostly because of the inclusion of a control condition, where there is no influence source, and a condition where there is just one influence source. Where the individual is confronted with a unanimous majority (that is, where the number of influence sources is two or more), the curvilinear form of these models is much less pronounced and little different from a simple linear relationship.

Although these theories mostly propose a single functional relationship between group size and social influence, Stasser and Davis (1981) propose that the form of the relationship will differ depending on whether the response to conformity pressure is public or private. Campbell and Fairey (1989) also propose different functions depending on which process predominates. When the process is essentially one of informational influence, they argue that the function will be like that of SIT, since the first source provides the most information and each additional source is less valuable because its judgments provide essentially redundant information. When the process is one of normative influence, the function will be S-shaped like SIM since the second and third sources should have greater impact than the first. Disagreement with one other equal status individual is a relatively common occurrence that carries no particular social stigma, and hence there is little normative pressure. It is only as group size gets larger, and the individual finds that they are in disagreement with several others, that normative pressure becomes operative.

Whether normative or informational influence will predominate will depend on a number of characteristics of the task, the group and the respondent. For example, Deutsch and Gerard (1955) argued that private responses are likely to be under the control of informational influence, and to be relatively unaffected by normative influence, whereas public responses will be affected by both. It is likely that some experimental paradigms will create stronger normative pressures than others. Face-to-face interaction in the Asch paradigm, for example, is likely to involve greater normative pressures than communication solely by means of a control panel as is used in the Crutchfield paradigm. There is evidence that conformity is higher in face-to-face groups than in simulated groups (Deutsch \& Gerard, 1955; Levy, 1960). Fictitious norm studies where respondents receive feedback on prior responses of people no longer present would involve even weaker normative pressures.

\section{Review of studies on group size and conformity}

Surprisingly few conformity studies have systematically varied group size, despite it being one of the oldest, and most frequently debated, research questions in this area. Group size has been studied in a variety of social influence paradigms (Latané, 1981), but few studies emerge if we confine our review to the classic conformity paradigm where a single respondent confronts a unanimous majority. In contrast to some earlier reviews (e.g. Mullen, 1983; Tanford \& Penrod, 1984), we exclude studies where the majority is not unanimous, as this is likely to moderate the relationship with group size significantly, given that conformity can be more or less eliminated in these circumstances (Allen, 1975; Asch, 1955). These include studies that have investigated social support for nonconformity (see Allen, 1975, for a review), studies where an initial majority favoring one option rather than another is not unanimous (e.g. Chapko \& Revers, 1976, 1978; Mackie, 1987, Experiment 2), and field studies of craning and gawking (e.g. Milgram, Bickman, \& Berkowitz, 1969) and queuing behavior (e.g. Mann, 1977).

Given this focus, conformity studies that have manipulated majority size are summarized in Table 1 , and it can be seen that there are only 16 studies in total. These cover a range of different tasks and contexts, but there are too few studies to judge what factors might moderate 


\begin{tabular}{|c|c|c|c|c|c|}
\hline Study & Task & Respondents & $\begin{array}{l}\text { Type of } \\
\text { response }^{\mathrm{a}}\end{array}$ & $\begin{array}{l}\text { Majority } \\
\text { sizes }\end{array}$ & Results \\
\hline \multicolumn{6}{|c|}{ Studies using Asch paradigm } \\
\hline Asch $(1951,1955)$ & Line judgment & $\begin{array}{l}\text { Male } \\
\text { undergraduates } \\
(N=144)^{\mathrm{b}}\end{array}$ & Public & $\begin{array}{l}1,2,3,4 \\
8,10-15^{c}\end{array}$ & Asymptotes at majority size of 3 \\
\hline $\begin{array}{l}\text { Insko, Smith, Alicke, } \\
\text { Wade, \& Taylor (1985) }\end{array}$ & Color judgment & $\begin{array}{l}\text { Female } \\
\text { undergraduates } \\
(N=203)\end{array}$ & Public \& private & 1,4 & $\begin{array}{l}\text { Effect greatest for public response } \\
\text { compared to private, and when } \\
\text { believed a verifiably correct answer }\end{array}$ \\
\hline Kumar (1983) & Dot estimation & $\begin{array}{l}\text { Boys aged } 9-10 \text { yrs } \\
(N=40) \text { and } 14-15 \text { yrs } \\
(N=40)\end{array}$ & Public & 5,10 & $\begin{array}{l}\text { Greater conformity for majority of } \\
10 \text { compared to } 5 \text { for young (aged } \\
9-10 \text { yrs) but not for old (14-15 yrs) }\end{array}$ \\
\hline \multicolumn{6}{|c|}{ Studies using Crutchfield paradigm } \\
\hline $\begin{array}{l}\text { Campbell \& Fairey } \\
\text { (1989) }\end{array}$ & Dot estimation & $\begin{array}{l}\text { Male and female } \\
\text { undergraduates } \\
(N=210)\end{array}$ & Public \& private & $0,1,3$ & $\begin{array}{l}\text { When attention low and norm moderate, } \\
\text { greatest difference between majority size } \\
\text { of } 0 \text { and } 1 \text {; when attention high and norm } \\
\text { extreme greatest difference between } 1 \text { and } \\
3\end{array}$ \\
\hline $\begin{array}{l}\text { Gerard, Wilhelmy, \& } \\
\text { Conolley (1968) }\end{array}$ & Line judgment & $\begin{array}{l}\text { Male }(N=88) \text { and } \\
\text { female }(N=66) \\
\text { undergraduates }\end{array}$ & Private & $2,3,4,5,6,7$ & Positive linear relationship \\
\hline $\begin{array}{l}\text { Horowitz \& Rothschild } \\
\text { (1970) }\end{array}$ & Line judgment & $\begin{array}{l}\text { Male }(N=90) \\
\text { undergraduates }\end{array}$ & Public & 2,4 & $\begin{array}{l}\text { Greater error when majority size is } 4 \\
\text { than when it is } 2\end{array}$ \\
\hline Nikols (1965) & $\begin{array}{l}\text { Line judgment and } \\
\text { geometric figures }\end{array}$ & $\begin{array}{l}\text { Female }(N=176) \\
\text { undergraduates }\end{array}$ & Public & 1,3 & $\begin{array}{l}\text { Greater conformity for majority size of } \\
3 \text { compared to } 1 \text { for both types of task }\end{array}$ \\
\hline Nordholm (1975) & Cue utilization & $\begin{array}{l}\text { Female }(N=140) \\
\text { undergraduates }\end{array}$ & Public & $1,2,3,4$ & Positive linear relationship \\
\hline Reitan (1969) & $\begin{array}{l}\text { Judging size of } \\
\text { geometric figures }\end{array}$ & $\begin{array}{l}\text { Female }(N=144) \\
\text { undergraduates }\end{array}$ & Public & $1,2,3$ & $\begin{array}{l}\text { Curvilinear relationship: difference } \\
\text { between majority sizes of } 1 \text { and } 2 \text { but not } \\
\text { between } 2 \text { and } 3\end{array}$ \\
\hline Rosenberg (1961) & Line judgment & $\begin{array}{l}\text { Male }(N=227) \\
\text { undergraduates }\end{array}$ & Public & $1,2,3,4$ & $\begin{array}{l}\text { Curvilinear relationship: decrease between } \\
\text { majority size of } 3 \text { and } 4\end{array}$ \\
\hline Stang (1976) Study 1 & Opinion items & $\begin{array}{l}\text { Male }(N=57) \\
\text { undergraduates }\end{array}$ & Public & $1,2,3,4$ & Positive linear relationship \\
\hline
\end{tabular}


Table 1. Continued

\begin{tabular}{|c|c|c|c|c|c|}
\hline Study & Task & Respondents & $\begin{array}{l}\text { Type of } \\
\text { response }^{\mathrm{a}}\end{array}$ & $\begin{array}{l}\text { Majority } \\
\text { sizes }\end{array}$ & Results \\
\hline \multicolumn{6}{|c|}{ Studies using a fictitious norm paradigm } \\
\hline Goldberg (1954) & $\begin{array}{l}\text { Judging intelligence } \\
\text { from photographs } \\
\text { (Majority present) }\end{array}$ & $\begin{array}{l}\text { Male college or high } \\
\text { school students or } \\
\text { businessmen }(N=79)\end{array}$ & Private & 2,4 & No difference \\
\hline Kidd (1956) & $\begin{array}{l}\text { Estimate number of } \\
\text { flickers of a light } \\
\text { (Majority present) }\end{array}$ & $\begin{array}{l}\text { Female }(N=100) \\
\text { and male }(N=82) \\
\text { undergraduates }\end{array}$ & Private & $2,4,6$ & No difference \\
\hline $\begin{array}{l}\text { Latané \& Davis, cited } \\
\text { in Latané \& Wolf (1981) }\end{array}$ & $\begin{array}{l}\text { Opinion items } \\
\text { (Majority absent) }\end{array}$ & $\begin{array}{l}\text { Male and female } \\
\text { undergraduates } \\
(N=1,008)\end{array}$ & Private & $0,1,2,3,6,12$ & $\begin{array}{l}\text { Curvilinear relationship: monotonic } \\
\text { negatively increasing }\end{array}$ \\
\hline Stang (1976) Study 2 & $\begin{array}{l}\text { Opinion items } \\
\text { (Majority absent) }\end{array}$ & $\begin{array}{l}\text { Male and female } \\
\text { undergraduates } \\
(N=30)\end{array}$ & Private & $1,4,8$ & $\begin{array}{l}\text { Curvilinear relationship: increase for } \\
\text { majority size from } 1 \text { to } 4 \text {, but decrease } 4 \\
\text { to } 8\end{array}$ \\
\hline Stang (1976) Study 3 & $\begin{array}{l}\text { Opinion items } \\
\text { (Majority absent) }\end{array}$ & $\begin{array}{l}\text { Male and female } \\
\text { undergraduates } \\
(N=300)\end{array}$ & Private & $0,4,8,12$ & $\begin{array}{l}\text { Curvilinear relationship: increase from } \\
\text { majority size of } 0 \text { to } 4 \text {, but no increase } \\
\text { from } 4 \text { to } 8 \text { to } 12\end{array}$ \\
\hline
\end{tabular}

a Public $=$ believes response will be made available to the other group members, Private= believes response will not be made available to the other group members.

b The sample size is from Asch (1951). Sample sizes are not given in Asch (1955).

c Asch (1951) gives the largest majority size as 16 whereas Asch (1952b) gives it as 10-15. 
the relationship. The table also shows that the range of majority sizes employed is limited. More than half of the studies employ a majority size no greater than 4 and only three employ a majority size greater than 10 . Three studies compare a majority with dyadic influence and do not, therefore, address the issue of the effect of different majority sizes.

The major sources, and those most frequently cited, are Asch's (1951, 1955) research, which concluded that there is no increase in influence beyond a majority of size three, and Gerard et al. (1968), which, in contrast, concluded that the relationship between majority size and conformity was linear. There are, however, problems with both of these studies which are frequently overlooked.

Given the pre-eminent status of Asch's (1951, $1955,1956)$ conformity experiments, it is surprising to find inconsistencies in the reports of what size of majority was employed. ${ }^{3}$ The reports of his main experiments variously describe the size of majority as 7 (Asch, 1951, p. 178), or as 8 (Asch, 1951, p. 181), or as between 6 to 8 (Asch, 1955, p. 22), or as being 6,7 and 9 (Asch, 1955, p. 35), or of 7 to 9 persons, but '. ... in a few instances the majority had only five or six members' (Asch, 1956, p. 5). The reports of the effect of group size are also inconsistent. In Asch (1951), experiments using six different majority sizes-1, 2, 3, 4, 8, and 16-are discussed. When the paper was reprinted a year later (Asch, 1952b), however, the largest majority is changed to indicate 10-15 rather than 16. Whereas in Asch (1951), the results for a majority size of 8 has the largest number of respondents $(n=50)$, there are no results for a majority size of 8 in Asch (1955), although there are results for majority sizes of 7 and 9. The reasons for these inconsistencies in Asch's reports can only be guessed at, although the practical difficulties in staging the paradigm may have been a factor. Nevertheless, they undermine the confidence that can be placed in Asch's $(1951,1955)$ findings concerning majority size. Clearly, it is difficult to use Asch's results to estimate the form of the relationship between group size and conformity if his results cannot be tied to specific majority sizes.
The study by Gerard et al. (1968) confounds group size with gender, since the respondents for even numbered group sizes were all boys whereas those for odd numbered group sizes were all girls, a problem that has been overlooked in reanalyses using overall means, as carried out by Tanford and Penrod (1984) and by Latané and Wolf (1981). Although frequently compared to Asch (1951), this study employs both a different type of paradigm (Crutchfield rather than Asch) and uses private rather than public responses, differences which are likely to reduce normative influence significantly.

Overall, the set of studies detailed in Table 1 provide a mixed set of findings. Several have found no increase in conformity with increased majority size (Goldberg, 1954; Kidd, 1956; Kumar, 1983, older participants; Reitan, 1967; Stang, 1976, Study 3), and some have found a decrease (Rosenberg, 1961; Stang, 1976, Study 2). Many of the significant differences are between a majority and either one influence source or no influence source. Only seven studies have reported significant differences between different sizes of majority (Gerard et al., 1968; Horowitz \& Bertram, 1970; Kumar, 1983, younger participants; Nordholm, 1975; Rosenberg, 1961; Stang, 1976, Study 1; Latané and Davis, cited in Latané \& Wolf, 1981).

There is some evidence that other features of the task and setting may moderate the relationship. Insko, Smith, Alicke, Wade, and Taylor (1985) found that the effect of majority size was greatest when the respondent gave a public compared to private response, and when the respondent believed that there was a verifiable correct answer than when they believed no correct answer could be determined. Campbell and Fairey (1989) found that whether the effect of one influence source was greater than the effect of increasing the number of influence sources from one to three depended on the opportunities for viewing the stimulus and the discrepancy between the majority's judgment and the correct answer. When these were low, the effect of one influence source was greater, but when these were high, the effect of increasing the number of influence sources from one to three was greater. 
In sum, there is inconclusive evidence for the relationship between group size and conformity from studies that have directly varied majority size, and a limited range of majority sizes has been studied. The studies use a variety of tasks and settings that are likely to entail normative and informational influence to varying degrees, and it is difficult to judge how comparable the findings are. For example, studies using a Crutchfield paradigm typically obtain public responses on perceptual tasks, and rarely employ a majority size greater than four, whereas fictitious norm studies obtain private responses and mostly use opinion items, and have employed a wider range of majority sizes. Majority size will not be as salient in fictitious norm studies where there is a single presentation of others' responses, sometimes as a summary statistic. There are too few studies using an Asch paradigm to judge whether faceto-face interaction with the majority is a significant moderator. Hence, there are important differences between the studies that may explain different findings.

\section{Meta-analyses}

Another source of evidence derives from metaanalysis. Two types of meta-analysis can be performed and one of each has addressed the issue of conformity and group size. The first, a 'within study' analysis, involves selecting conformity studies in which group size has been varied and estimating the size of the relationship between group size and conformity in each study. Meta-analytic methods are used to combine these estimates to form an overall estimate of the size of the relationship in the population of studies. The meta-analysis by Mullen (1983) is of this type. He sampled 12 conformity studies which have manipulated group size, computed the correlation between the OTR and conformity for each study, and found that the average $R^{2}=.78$.

The success of this type of analysis relies on there being a sufficient number of studies where majority size has been varied. However, as we have seen from Table 1, few such studies exist. In order to find as many as 12, Mullen (1983) includes a much more heterogeneous set of studies than is considered in this review. Thus, he includes a study concerned with minority influence where there is a majority of naive respondents (Nemeth, Wachtler, \& Endicott, 1977), field studies of craning and gawking (Milgram et al., 1969) and queuing behavior (Mann, 1977), and studies where the majority was not unanimous (Chapko \& Revers, $1976,1978)$. The difficulty with this approach is that there are good reasons for supposing that different processes operate when, for example, there is social support (Allen, 1975) or when there is minority rather than majority influence (Moscovici, 1980). The relationship between majority size and conformity may well differ depending on what process predominates, and this may be obscured by combining such a heterogeneous set of studies.

Tanford and Penrod (1984) carried out a second type of meta-analysis. They adopt a 'between studies' approach, where they seek to explain differences in effect size between studies in terms of the different size of the majority employed. The advantage of this approach is that a much wider sample of studies can be used, including those not designed to investigate majority size. The disadvantage is that other between study differences may be confounded with majority size and, if not controlled for, produce misleading results. They selected just nine reports of conformity studies, some of which varied majority size and some of which varied the type of task. These are included in a single meta-analysis ${ }^{4}$ with studies of minority influence and with studies that compare majority and minority influence. They conclude that their SIM provides a better fit than either SIT or a simple linear model.

Similar objections to those made to Mullen (1983) can be raised with respect to Tanford and Penrod's (1984) analysis. Given the heterogeneity of tasks and settings, it is likely that the predominant social influence process will vary between studies and that the relationship between majority size and influence may vary depending on what that predominant process is. There are also possible sources of confounding between studies since, although several control variables are included in the analysis, 
other potentially important variables are not included. For example, respondents' gender was not controlled for even though this is significantly related to conformity (Bond \& Smith, 1996; Eagly \& Carli, 1981).

Research on group size and conformity has, then, yielded inconclusive findings. The next section presents a meta-analysis of studies using Asch's (1952a, 1956) line judgment task which safeguards against confounding the variables of interest with task characteristics, and enables control of other potential moderating variables that previous research has shown to be important with this task. In spite of this restriction, a large number of studies can be analyzed because Asch's research has been so influential that many studies have been carried out using his materials.

We are also able to investigate whether the relationship between group size and conformity varies depending on whether normative or informational influence predominates. Asch's line judgment task has been used both in studies using an Asch paradigm and studies using a Crutchfield paradigm, and it is likely that normative influence will be stronger in the former than in the latter. The task has not, however, been used with a fictitious norm paradigm, and therefore it is not possible to investigate this paradigm in this analysis. It has also been used with both public and private responses to group pressure and, likewise, normative influence is likely to be stronger with public rather than private responses. Thus, normative influence is likely to be strongest where the participant must make a public response in face-to-face interaction with the majority. Informational influence is likely to predominate when the participant makes a private response, and is not in view of the majority. Hence, our aim is to provide further evidence for the relationship between group size and conformity by a 'between studies' metaanalysis which exercises a good deal of control over other variables, and to investigate whether the relationship varies, as proposed, depending on the type of experimental paradigm and type of response.

\section{The relationship between group size and conformity in studies using Asch's (1952b, 1956) line judgment task}

\section{Sample of studies and coding of variables}

The studies used in this research were those reported in a meta-analysis concerned with culture and conformity reported in Bond and Smith (1996), except that review excluded results from a majority size of one but these are included here. Full details of the literature search, criteria for inclusion, coding of variables and a discussion of the computation and analysis of effect sizes can be found in that report. A search of PsycINFO 1993-2003 found no additional studies that met the criteria for inclusion.

In sum, replications of the Asch experiment were sought, but included experiments that had used a Crutchfield apparatus. The criteria for inclusion were that (a) the task involves judging which of three comparison lines is the same length as a standard, (b) the experiment employs a group pressure paradigm in which the participant is confronted with the erroneous responses of a majority who are also present, (c) the participant is alone against a unanimous majority, (d) the majority consists of one or more individuals, (e) the participants are adults (i.e. at least 17 years of age) and (f) the participants are not suffering any form of psychopathology or severe learning disability. Studies, and different experimental conditions of studies, were included that varied in terms of the following moderator variables: majority size, relation of the participant to the majority group, whether a participant's response would be known to the majority, the gender of the participant and stimulus materials that varied in terms of the consistency of the deviant response by the majority and in terms of the average magnitude of error. Experimental conditions that varied in terms of these moderator variables were entered as separate studies in the analysis. Studies (or experimental conditions of studies) were excluded, however, that introduced other potential moderator variables that were specific to one or two studies: for example, 
asking the participant first to write down his or her answer (Deutsch \& Gerard, 1955), offering a reward to the group that is most accurate (Deutsch \& Gerard, 1955; Frager, 1970), removing the stimuli before eliciting the responses (Deutsch \& Gerard, 1955), showing either a violent or peaceful film prior to the judgment task (Hatcher, 1982) or varying the instructions and using a different task first (Wagner \& Shaw, 1973).

In total, 62 reports produced 125 separate experiments that were used in this analysis. ${ }^{5}$ For ease of exposition, we shall refer to these as studies in the remainder of this article.

For each study, the following information was coded: (a) the country in which the study was conducted; (b) the year in which the study was conducted (where this was not given, it was taken as two years before the publication date in the case of articles and one year before in the case of doctoral dissertations); (c) the type of experimental paradigm (Asch-type, i.e. face-to-face using confederates, or Crutchfieldtype, i.e. individual booths with false feedback of other group members' responses); (d) majority size; (e) the relation of the majority to the participant (acquaintances, strangers, outgroup members, both in-group and out-group members); (f) whether the participant's response was available to the majority; $(\mathrm{g})$ the stimulus materials (Asch, 1952a, with or without minor modification; Asch, 1956, with or without minor modification; or unique materials); (h) the total number of trials; (i) consistency, defined as the ratio of critical trials to the total; ( $\mathrm{j}$ ) stimulus ambiguity, defined as the average error in centimetres; $(\mathrm{k})$ the percentage of female respondents; and (l) the participant population.

The effect size calculated was a modified form of $g$ (Hedges \& Olkin, 1985) whereby the difference between the experimental and the control group in mean number of errors is divided by the $S D$ in the experimental group. Further discussion of this choice of measure of effect size and the implications for the meta-analysis can be found in Bond and Smith (1996, p. 117).

\section{Study characteristics}

The main characteristics of the sample of studies are summarized in Table 2. The large majority (78\%) were conducted in the United States, two-thirds use an Asch paradigm and one-third a Crutchfield paradigm, and most $(88 \%)$ obtain public rather than private responses. Half the studies use Asch's (1956) stimulus materials, some with minor modifications, although a significant minority of replications $(n=23)$ used Asch's (1952a) pilot materials rather than those developed for the main program of his research. Half the studies use all men, and a quarter use all women. In two-thirds of studies the majority are strangers to the participant (although probably student peers).

Aside from Asch's (1951, 1952b) condition with the largest majority (either 16 or $10-15$ depending on which article is used as the source), it is noteworthy that there is no study that uses a majority size greater than 9 . This is a significant limitation in the literature on conformity and majority size, since the majority sizes investigated cover such a limited range. The modal size of majority employed is 3 , reflecting Asch's (1951) assertion that 3 is sufficient for maximum effect, and two-thirds of the studies use a majority size of 4 or less. Of the larger majority sizes, the most frequently employed is 8 , the number normally associated with Asch's (1956) main experiment.

The unweighted mean effect size was 1.03 and the median was 0.94 ; the weighted mean effect size was 0.89 (95\% confidence interval $=$ 0.85 to 0.93$)$. This indicates that on average there is a large conformity effect when comparing conditions of majority influence with the control condition. The test for homogeneity was rejected $(Q=427.25, d f=124, p<.01)$, indicating significant heterogeneity among the effect sizes. This was expected because the studies varied in terms of several moderator variables, including majority size.

\section{Conformity and majority size}

It was argued that the relationship between conformity and majority size may well depend 
Table 2. Summary of study characteristics

\begin{tabular}{|c|c|c|c|}
\hline Variable and class & Value & Variable and class & Value \\
\hline \multicolumn{2}{|l|}{ Majority size } & \multicolumn{2}{|l|}{ Stimulus materials } \\
\hline 1 & 4 & Asch (1952b) & 16 \\
\hline 2 & 5 & Modified Asch (1952b) & 7 \\
\hline 3 & 49 & Asch (1956) & 44 \\
\hline 4 & 22 & Modified Asch (1956) & 19 \\
\hline 5 & 7 & Unique & 39 \\
\hline 6 & 9 & \multicolumn{2}{|l|}{ Consistency } \\
\hline 7 & 8 & Less than $50 \%$ & 3 \\
\hline 8 & 19 & $50 \%-59 \%$ & 33 \\
\hline 9 & 1 & $60 \%-69 \%$ & 59 \\
\hline $10-15$ & 1 & $70 \%-79 \%$ & 3 \\
\hline \multicolumn{2}{|l|}{ Experimental paradigm } & $80 \%$ and higher & 27 \\
\hline Asch-type & 85 & \multicolumn{2}{|l|}{ Country } \\
\hline Crutchfield-type & 40 & United States & 98 \\
\hline Type of response & & Great Britain & 9 \\
\hline Public & 110 & Belgium & 4 \\
\hline Private & 15 & France & 2 \\
\hline \multicolumn{2}{|l|}{ Percentage of women participants } & Holland & 1 \\
\hline All men & 64 & Germany & 1 \\
\hline $26 \%-50 \%$ & 9 & Canada & 1 \\
\hline $51 \%-75 \%$ & 7 & Portugal & 1 \\
\hline All women & 30 & Brazil & 1 \\
\hline \multirow[t]{4}{*}{ Not codable } & 15 & Hong Kong & 1 \\
\hline & & Zimbabwe & 1 \\
\hline & & Japan & 3 \\
\hline & & Fiji & \\
\hline \multicolumn{2}{|l|}{ Relation of majority to participant } & Mean average error (ins.) & 1.19 \\
\hline Acquaintances/friends & 10 & Not codable & 17 \\
\hline Strangers & 79 & & \\
\hline Out-group members & 12 & Median date of study & 1966 \\
\hline Mix of in-group and out-group & 23 & & \\
\hline Not codable & 1 & & \\
\hline
\end{tabular}

Note: For categorical variables, the numbers in the table represent the frequency of studies in each class.

on the type of paradigm (Asch compared with Crutchfield) and the type of response (public compared with private). To investigate this, a continuous model on effect sizes was fitted whereby weighted least-squares estimators of regression coefficients were obtained by weighting each effect size by the reciprocal of its estimated variance (Hedges \& Olkin, 1985, p. 174). The independent variables were majority size, type of paradigm, type of response, all two-way interactions involving these variables, and the three-way interaction. Several variables were included as covariates in order to control for a number of moderator variables that Bond and Smith (1996) found were significantly related to conformity effect size: (a) the percentage of female respondents, (b) the date when the study was carried out, (c) the consistency of the majority (i.e. the ratio of critical trials to the total number of trials), (d) whether the majority were an out-group for the respondent, and (e) stimulus ambiguity (i.e. the difference in length between the comparison line and the stimulus line chosen by the majority). To control for the effects of culture, each study was coded on Schwartz's (1994) dimensions of 
(Latané \& Wolf, 1981; Mullen, 1983; Tanford \& Penrod, 1984) is that a curve is needed to fit the small or nonexistent effects in the control condition where there are no influence sources, and the condition of dyadic influence where there is one influence source. By running separate analyses, the impact of including conditions of dyadic influence could be evaluated.

Table 4 presents the $R^{2}$ values for these various models. Where studies with one influence source were excluded, it is evident that none of the curvilinear models provide an appreciably better fit than the simple linear model. Only in studies employing a Crutchfield paradigm and private responses do the curvilinear models perform marginally better than the linear model, especially OTR. For studies employing an Asch paradigm or a Crutchfield paradigm and public response, the OTR, SIT and SIM models do no better than the linear model, and the addition of a quadratic term provides very little, if any, improvement. The reduction in the homogeneity statistic provides a test of whether the addition of a quadratic term results in a significant improvement in fit over a linear model and this was not significant for each combination of type of paradigm and type of response (Asch-Public, $Q_{\text {CHANGE }}=1.93$, $d f=1, n s$; Asch-Private, $Q_{\text {CHANGE }}=0.00, d f=1$, $n s$; Crutchfield-public, $Q_{\text {CHANGE }}=0.08, d f=1$, $n s$; Crutchfield-private, $Q_{\text {CHANGE }}=0.38, d f=1$, $n s) .{ }^{8}$ Comparison of the homogeneity statistics

Table 4. Linear and curvilinear models of conformity and majority size: Comparison of $R$-squared values

\begin{tabular}{|c|c|c|c|c|c|}
\hline & $\begin{array}{c}\text { Linear } \\
R^{2}\end{array}$ & $\begin{array}{c}\text { Quadratic } \\
R^{2}\end{array}$ & $\begin{array}{c}\text { Other- } \\
\text { Total Ratio } \\
R^{2}\end{array}$ & $\begin{array}{c}\text { Social Impact } \\
\text { Theory }^{\mathrm{b}} \\
R^{2}\end{array}$ & $\begin{array}{c}\text { Social } \\
\text { Influence } \\
\text { Model }^{\mathrm{c}} \\
R^{2}\end{array}$ \\
\hline \multicolumn{6}{|c|}{ Excluding studies where majority size $=1$} \\
\hline \multicolumn{6}{|l|}{ Asch paradigm } \\
\hline Public $(N=79)^{\mathrm{d}}$ & .086 & .094 & .062 & .078 & .022 \\
\hline Private $(N=4)$ & .993 & .994 & .990 & .994 & .975 \\
\hline \multicolumn{6}{|c|}{ Crutchfield paradigm } \\
\hline Public $(N=28)$ & .014 & .015 & .020 & .015 & .029 \\
\hline Private $(N=10)$ & .255 & .290 & .304 & .273 & .310 \\
\hline \multicolumn{6}{|c|}{ Including studies where majority size $=1$} \\
\hline \multicolumn{6}{|l|}{ Asch paradigm } \\
\hline Public $(N=81)^{\mathrm{e}}$ & .110 & .110 & .123 & .114 & .101 \\
\hline \multicolumn{6}{|c|}{ Crutchfield paradigm } \\
\hline Public $(N=29)$ & .025 & .032 & .041 & .030 & .052 \\
\hline Private $(N=11)$ & .417 & .522 & .534 & .480 & .510 \\
\hline
\end{tabular}

Note: Models are estimated using weighted least-squares estimates of regression coefficients obtained by weighting each effect size by the reciprocal of its estimated variance (Hedges \& Olkin, 1985, p. 174).

a In conformity experiments where a lone respondent is confronted by an unanimous majority, the other-total ratio is given as $M /(M+1)$ (Mullen, 1983).

b The function used for the social impact model was $I=M^{0.45}$ where $I=\operatorname{impact}$ and $M=$ majority size. The choice of 0.45 for the exponent follows Tanford and Penrod's (1984) conclusion that this was most appropriate for modeling conformity experiments.

c The function used for the social influence model was $I=\exp \left(-4 \times \exp \left(-\mathrm{N}^{1.175}\right)\right)$ where $I=\operatorname{impact}$, and $N=$ number of sources (Tanford \& Penrod, 1984, p. 198).

d If Asch's $(1951,1956)$ four studies using majorities of 8 and 10-15 are excluded, the $R^{2}$ values are: Linear $=$ .072 , Quadratic $=.126$, Other-Total Ratio $=.048$, Social Impact Theory $=.064$, Social Influence Model $=.016$.

e If Asch's $(1951,1956)$ four studies using majorities of 8 and $10-15$ are excluded, the $R^{2}$ values are: Linear $=$ .098 , Quadratic $=.100$, Other-Total Ratio $=.109$, Social Impact Theory $=.101$, Social Influence Model $=.093$. 
from the OTR, SIM or SIT with that from the linear model found that none provided a significantly better fit (Asch-Public: OTR, $F_{(79,79)}=$ 1.03 , SIT, $F_{(79,79)}=1.00$, ns; SIM, $F_{(79,79)}=1.01$, $n s$; Asch-Private: OTR, $F_{(2,2)}=1.56$, SIT, $F_{(2,2)}<$ 1 , ns; SIM, $F_{(2,2)}=3.78$, ns; Crutchfield-Public: OTR, $F_{(27,27)}<1$, SIT, $F_{(27,27)}<1$, ns; SIM, $F_{(27,27)}$ $<1$, ns; Crutchfield-Private: OTR, $F_{(9,9)}<1$, SIT, $F_{(9,9)}<1, n s$; SIM, $\left.F_{(9,9)}<1, n s\right)$.

The inclusion of studies where there is one influence source does not affect the results appreciably for studies of public responses using either an Asch or Crutchfield paradigm, and there are no studies using a majority size of one for private responses in an Asch paradigm. For studies employing a Crutchfield paradigm and private response, however, the inclusion of the additional study with a majority size equal to one led to all models providing a better fit (the increases in $R^{2}$ values range from .16 to .23 compared to when the study was excluded). It was also found that the curvilinear models provide a better fit than the simple linear model (the increases in $R^{2}$ values range from .06 to .12), although the reduction in the homogeneity statistic with the inclusion of the quadratic term compared to the linear model is not significant $\left(Q_{\text {CHANGE }}=1.72 . d f=1, n s\right)$.

A second reason why previous analyses have favored curvilinear models is the inclusion of the control condition (i.e. where the number of influence sources equals zero) where in Aschtype studies the experiment is designed to ensure that respondents make virtually no errors and hence the effect size is near zero. In this meta-analysis, the control condition is used in the calculation of each effect size, but a comparable analysis was carried out by forcing the regression through the origin (i.e. the point of zero majority size and zero effect size). When this is done, curvilinear models generally provide a better fit than the linear model, although the improvement in $R^{2}$ values is modest ranging from .046 to .081 .

On the whole, then, curvilinear models do not provide a better fit than a linear model if analyses are confined to variations in majority sizes of two or more. There is some evidence of modest improvements in fit when dyadic influence is included and when regression is forced through the origin so that it takes on a zero effect size in the control condition. It is important, therefore, to distinguish the question of what is the relationship between increases in majority size and conformity, from that of what is the effect of group pressure (the difference between the majority and the control) and what is the relation between majority influence, dyadic influence and no influence.

To investigate further the three-way interaction involving majority size, type of paradigm and type of response, the weighted mean adjusted effect sizes by majority size for each type of paradigm and type of response are given in Table 5. Table 6 shows the continuous linear models for effect sizes on majority size for each type of paradigm and type of response. Studies where 'majority' size equals one are included in Table 5 but were excluded from the regression analyses reported in Table 6 for the reasons given above.

\section{Majority size and public conformity}

Asch paradigm For public responses in the Asch paradigm the relationship between conformity and majority size is significant, but is weak nevertheless. The correlation is low $(r=$ .29) and the significant value for the homogeneity statistic indicates that the model is not adequately specified. There is significant variation in effect sizes but this is not accounted for by variation in majority size. The slope of the regression line, $b=0.057$, is modest such that an increase in majority size of 10 would lead to an expected increase in effect size of just over half of a standard deviation. Inspection of the means in Table 5 show that it is only the small effect size for the one study with a majority size of 2, and the somewhat larger effect sizes for studies employing a majority size of 8 , that gives the regression line its positive slope. Mean effect sizes for majority sizes of 3, 4, 5, 6 and 7 are very similar, and give some support to Asch's (1951) contention that a majority of 3 is sufficient.

Crutchfield paradigm The results for public responses in a Crutchfield paradigm are similar 
Table 5. Weighted mean adjusted effect sizes by majority size

\begin{tabular}{|c|c|c|c|c|c|c|c|c|c|c|}
\hline & \multicolumn{10}{|c|}{ Majority size } \\
\hline & 1 & 2 & 3 & 4 & 5 & 6 & 7 & 8 & 9 & $10-15$ \\
\hline \multicolumn{11}{|l|}{ Asch paradigm } \\
\hline Public response & -.17 & 0.44 & 0.86 & 0.68 & 1.12 & 0.58 & 0.95 & 1.19 & & 1.16 \\
\hline$N=81$ & $(2)$ & (1) & $(25)$ & $(16)$ & $(5)$ & $(6)$ & $(7)$ & $(18)$ & & (1) \\
\hline Private response & & & 1.47 & & & & & 0.75 & 0.63 & \\
\hline$N=4$ & & & $(2)$ & & & & & (1) & $(1)$ & \\
\hline \multicolumn{11}{|l|}{ Crutchfield paradigm } \\
\hline Public response & 0.61 & 0.81 & 0.99 & 0.94 & 0.49 & 1.19 & & & & \\
\hline$N=29$ & $(1)$ & (3) & $(17)$ & $(5)$ & $(1)$ & $(2)$ & & & & \\
\hline Private response & 0.40 & 0.66 & 0.99 & 1.24 & 0.95 & 1.31 & 1.24 & & & \\
\hline$N=11$ & $(1)$ & (1) & $(5)$ & $(1)$ & (1) & $(1)$ & $(1)$ & & & \\
\hline
\end{tabular}

Note: Effect sizes are weighted by the reciprocal of their variance. Number of effect sizes are given in parentheses. Effect sizes were adjusted to control for the effect of (a) the percentage of female respondents, (b) the date when the study was carried out, (c) the consistency of the majority (i.e. the ratio of critical trials to the total number of trials), (d) whether the majority were an out-group for the respondent, (e) stimulus ambiguity (i.e. the difference in length between the comparison line and the stimulus line chosen by the majority), and (f) Schwartz's (1994) measures of Affective Autonomy, Intellectual Autonomy and Conservatism. Residuals from a continuous model using these moderators as predictor variables were computed and rescaled by adding the value predicted from the mean of each moderator variable.

to those of public responses in an Asch paradigm. The correlation between conformity and majority size is even weaker $(r=.12)$ and, since the homogeneity statistic is significant, the model is not adequately specified. The slope of the regression line $(b=0.03)$ is similar to that found for Asch paradigm studies, reinforcing the view that the impact of increasing majority size on public conformity is minimal, at least for the range of majority sizes that has

Table 6. Continuous linear models of conformity and majority size by type of paradigm and type of response

\begin{tabular}{|c|c|c|c|c|c|c|}
\hline \multirow[b]{3}{*}{ Majority size $(b)$} & \multicolumn{3}{|c|}{ Asch paradigm } & \multicolumn{3}{|c|}{ Crutchfield paradigm } \\
\hline & \multicolumn{2}{|l|}{$\begin{array}{c}\text { Public } \\
\text { response }\end{array}$} & $\begin{array}{c}\text { Private } \\
\text { response }\end{array}$ & \multicolumn{2}{|l|}{$\begin{array}{l}\text { Public } \\
\text { response }\end{array}$} & $\begin{array}{c}\text { Private } \\
\text { response }^{\mathrm{a}}\end{array}$ \\
\hline & 0.057 & $* *$ & $-0.141 \quad * *$ & 0.034 & $* *$ & 0.088 \\
\hline Constant & 0.609 & & 1.90 & 0.828 & & 0.680 \\
\hline$Q_{\mathrm{e}}$ & 213.76 & $* *$ & 0.04 & 78.32 & $* *$ & 8.16 \\
\hline$d f$ & 77 & & 2 & 26 & & 8 \\
\hline$r$ & .29 & & .997 & .12 & & .51 \\
\hline
\end{tabular}

$* * p<.01$.

Note: The model is a weighted least-squares estimate of regression coefficients obtained by weighting each effect size by the reciprocal of its estimated variance (Hedges \& Olkin, 1985, p. 174). $b$ equals the unstandardized regression weight. $Q_{\text {e }}$ equals the homogeneity statistic used to test model specification. When $Q$ is significant the hypothesis of adequate model specification is rejected. The models were derived from conducting separate analyses for each combination of type of paradigm and type of response excluding studies where majority size equals 1 .

a The model using the other-total ratio provided a better fit for this sample of studies than the simple linear model. The regression equation was $b=2.462$, constant $=-0.891, Q_{\mathrm{e}}=7.63, d f=8, r=.55$. 
been studied. It is noteworthy, however, that there has been no study in this category that has employed a majority size greater than 6 .

\section{Majority size and private conformity}

Asch paradigm Only four studies have recorded private responses in the Asch paradigm, and the adjusted effect sizes fall almost exactly on a straight line, giving $r=-.997$ and a nonsignificant homogeneity statistic indicating adequate model specification. Increasing majority size is associated with a significant decrease in private conformity.

Crutchfield paradigm The relationship between majority size and private conformity is strikingly different from that for public conformity, although many fewer studies have recorded private rather than public responses. Results for the 10 studies using the Crutchfield paradigm show a fairly strong linear relationship with $r=.51$ and the nonsignificant homogeneity statistic indicating adequate model specification. Variation in these effect sizes is adequately accounted for by variation in majority size. The slope of the regression line $(b=0.09)$ is steeper than for public responses, indicating that increasing majority size has a greater impact.

\section{Type of paradigm and type of response}

It is sometimes assumed that conformity is greater when the respondent must make a public response in face-to-face interaction with the majority, and some previous research has supported this view (e.g. Insko et al., 1985; Levy, 1960). This is not supported by this metaanalysis, however. Of course, the presence of a three-way interaction implies that comparisons on any one factor will vary depending on the values of the other two factors. So, for example, the difference in conformity according to type of paradigm depends both on majority size and type of response. Nevertheless, the mean effect sizes presented in Table 5 , and the results of the regression analyses presented in Table 6 , show that effect sizes are broadly comparable across Asch and Crutchfield paradigms, and across public and private responses. In contrast to what might have been expected, for majority sizes of 6 or greater, the largest predicted effect size is for studies employing private responses in the Crutchfield paradigm. For public responses, studies using a Crutchfield paradigm have slightly higher predicted effect sizes than those using an Asch paradigm for majority sizes less than 10 .

\section{Discussion and conclusions}

Theories on the relationship between majority size and conformity have all suggested that it will take on a single particular form, whereas the main argument of this review is that the form of the relationship will vary according to the social influence process elicited by the task and setting. The review of the literature revealed that empirical evidence detailing the relationship is weak. Few studies have investigated the relationship directly, and they have yielded mixed and inconclusive findings, in part because different paradigms and tasks are likely to have elicited different processes. Previous meta-analyses also have assumed a single form of relationship, and consequently have combined results across heterogeneous sets of studies, rather than examining the possibility that the form of relationship might vary depending on study characteristics. Thus, the narrative review has shown that it is difficult to draw any conclusions about this relationship, which highlights the need for a more focused examination of the kind provided by the metaanalysis reported here.

This meta-analysis indicates that the relationship varies depending on the type of paradigm and type of response. For public responses, there is a weak positive, linear relationship between conformity and majority size both in Asch and Crutchfield paradigms. For private responses, there is a strong positive relationship in the Crutchfield paradigm, but in the Asch paradigm the evidence from the four studies in this review suggests that the relationship may be negative. Just how robust these conclusions are, however, must await further research.

This meta-analysis has sought to explain differences in effect size between conformity 
studies in terms of the different majority sizes employed and, by restricting the meta-analysis to studies using Asch's line judgment task, it has been possible to control for task characteristics and for several moderator variables known to affect conformity in this experimental paradigm. Nevertheless, there is always the possibility that there are other differences between studies confounded with majority size. Conformity can be affected by a number of subtle features of the task that cannot be identified from the published report of the study and the drawing of causal inferences from what is a correlational analysis is a hazardous business. Confidence in these findings would be greatly enhanced if backed up by findings from carefully controlled experimental studies.

A further limitation is that conformity studies using Asch's line judgment task (and probably conformity studies in general) have used only a limited range of majority sizes. Investigators were quick to seize on Asch's (1951) conclusion that 3 was a sufficient number for maximal effect and hence, as this review shows, 3 is the modal majority size employed in the literature. None other than Asch $(1951,1955)$ have employed a majority size of greater than 9 in the Asch paradigm, and in the Crutchfield paradigm the range of majority sizes is even narrower, most studies using majorities of between two and four. Further research needs to examine the effect of larger majority sizes if the form of the relationship is to be identified.

The lack of evidence for curvilinear models is in contrast to Asch $(1951,1955)$ and to earlier reviews of this literature (Latané \& Wolf, 1981; Tanford \& Penrod, 1984), but the conclusion that a linear model is adequate rests on not including the control condition. If the control condition is included (or, where the control mean is incorporated into the measure of effect size, if the regression is forced through the origin), then a curvilinear model will give a somewhat better fit. However, this highlights the need to distinguish the effect of increasing majority size from the fact that group pressure has an effect compared to an absence of group pressure. There was some evidence, for studies of public responses in a Crutchfield paradigm, that a curvilinear model also provided a better fit when a study of dyadic influence (i.e. one influence source) was included. The processes involved in dyadic influence have scarcely been explored in the literature, falling numerically between the dominant concerns with majority and minority influence, but this would be a fruitful topic for further research.

The negative relationship found for private responses in studies using an Asch paradigm had not been anticipated and must be treated with caution, given the small number of studies of this type. One explanation is the arousal of suspicion, and this is a factor that needs to be considered generally since it is likely to be confounded with majority size. It may not be surprising to find that a few others unanimously hold a view opposite to oneself, but it is a lot more surprising to find that several do. Therefore, the larger the numbers of people with whom we expect to agree but who nevertheless unanimously endorse a different view, the more likely it is that we will become suspicious.

Apart from suspicion, another explanation for the negative relationship may be reactance (e.g. Brehm, 1966; Moscovici, 1980). When there is strong pressure to conform, as in the Asch paradigm but less so in the Crutchfield paradigm, people may react against the majority in private but not in public because of normative pressures. Moscovici (1980) argued that majorities would not change people's private beliefs because individuals wish to assert their individuality and independence and, likewise, Brehm (1966) proposes that if people are under pressure to change their beliefs in one direction, they would move in the opposite direction to assert their individuality.

The relationship between conformity and majority size when the primary motive is to please others and to avoid negative sanctions requires further research. Although it seems reasonable to assume that the larger the size of the majority the greater the pressure to conform, the magnitude of such pressure is likely to depend on just who the majority are and on the context, and our results suggest that with public responses a small majority may be sufficient to exert near maximum pressure. Dyadic 
interaction may present a special case since, as Campbell and Fairey (1989) suggest, disagreement with one other is taken as relatively commonplace and hence exerts little normative pressure. Therefore, an S-shaped relationship between majority size and conformity may be found when one influence source is included.

When the primary motive is accuracy, Baron, Vandello, and Brunsman (1996) show that when people lack confidence in their initial judgment they will rely more on others' judgments in deciding what is the correct response. So people are more influenced by a majority when the task is difficult, and hence they are less confident of their initial judgement, than when it is easy. However, this is only if the task is important, and hence people are primarily motivated to be accurate. When the task is not important, and hence accuracy is no longer the predominant motive and other motives such as maintaining harmony are also important, people are no more likely to conform on a difficult task as on an easy task.

Since this meta-analysis has been confined to studies using Asch's line judgment task, where the correct answer is designed to be unambiguous, we would expect people to be less dependent on others than they would in paradigms using more ambiguous tasks. So we would expect to find a stronger relationship between majority size and conformity for tasks where people are more dependent on others for determining validity, compared to the weak positive relationship found here for public responses in both Asch and Crutchfield paradigms.

It will also depend on how the group is perceived, and in particular whether group members are seen as independent from one another. Even subtle cues as to whether people are seen as belonging together have been shown to affect conformity. Wilder (1977) found that when a group of individuals are identified as members of a 'discussion group' they are less influential than when the same number of people are described merely as an aggregate, even though the opinions presented are reached prior to any discussion.
Further research also needs to identify more carefully the circumstances under which particular motives will be aroused. We have assumed that normative pressures are greater in experimental paradigms where individuals are in face-to-face contact with the majority and where people make a public response that will be available to other group members. However, recent work has shown that this is not always necessarily the case. A concern to create a positive impression on others, or to maintain a consistent self-image, can be aroused in private contexts (Baldwin \& Holmes, 1987), just as public contexts can sometimes arouse a heightened desire for accuracy (Cowan \& Hodge, 1996; Lambert, Cronen, Chasteen, \& Lickel, 1996). Increasing task importance can increase the motive for accuracy, but when the task is relatively unimportant, people will be more motivated by the social consequences of their judgement (Baron et al., 1996). Certain individuals are more likely to be sensitive to the social consequences of their behavior, and hence more motivated to please others (e.g. those high in self monitoring, Lavine \& Snyder, 1996). Those in cultures with more collectivist values are more likely to be concerned with maintaining harmony (Bond \& Smith, 1996). Social identity theory (Tajfel, 1981, 1982) and self-categorization theory (Turner, 1991) emphasize that the implications of agreement or disagreement with others will depend on whether they are perceived as in-group or outgroup members.

In many ways, this review raises issues for further research rather than offers definitive answers. It has sought to reopen the question of the relationship between group size and conformity by questioning what we have learned from previous research and theory and by presenting a meta-analysis that identifies a more complex relationship than has been assumed hitherto. The task for future research is to identify more closely how majority size relates to social influence when different motives are aroused, as well as identifying how features of the task and setting elicit different motivations. 


\section{Notes}

1. Both SIT (Latané, 1981) and the Social Influence Model (SIM) (Tanford \& Penrod, 1984) are general theories of social influence which apply to a much broader range of phenomena than conformity. The focus here is just on the application of these theories to conformity and majority size.

2. The value of 1.75 for the exponent may be a misprint as we have found that a value of 1.175 better reproduces their results.

3. A more detailed account of the discrepancies in Asch's reports may be obtained from the author.

4. In fact, Tanford and Penrod (1984) perform simple regression analyses rather than using appropriate meta-analytic methods (Hedges \& Olkin, 1985).

5. Details of studies are given as Appendix A in Bond and Smith (1996). Four studies (Asch, 1952b; Asch, 1956; Gerard et al., 1968; and Nikols, 1965) included a majority size of one and these are included in this analysis although they had been excluded from Bond and Smith (1996).

6. It could be argued that four of Asch's (1951, 1956) studies, those with majority sizes of 8 and $10-15$, should be eliminated in view of the conclusion in the Review that these majority sizes did not always obtain. All analyses reported in this article have been run both with and without these studies. In all cases, the results are virtually identical, and we have reported the results including these studies in order to maximize the range of data values.

7. This two-stage approach will not give exactly the same results as would be obtained by entering all variables in a single analysis. For example, the regression coefficient for majority size in a regression analysis including the other control variables will be different from the regression analysis of majority size on the residuals from the model with the other control variables. This is because both majority size and the effect size are adjusted for their relationship to the control variables in the former analysis whereas only effect size is adjusted in the latter. However, the correlation between majority size and the other control variables was not large $(R=.39)$.

8. A model was fitted that also included a cubic term. This led to an improvement in fit for public responses in a Crutchfield paradigm where the $R^{2}$ value compared to the linear model improved from .03 to $.11, Q_{\text {CHANGE }}=7.05, d f=2, p<.05$. However, this is because of the improved fit for the much larger effect sizes for the two studies with a majority size of six, and is not the form of cubic relationship predicted by any theory of majority size and conformity. The cubic relationship predicted by SIM, which is derived from theory, does not provide a better fit to the data. The addition of a cubic term did not provide a significantly better fit for the other analyses by type of paradigm and type of response.

\section{Acknowledgment}

I would like to thank Helga Dittmar for her comments on a draft of this article.

\section{References}

References marked with an asterisk indicate studies included in the meta-analysis.

*Abrams, D., Wetherell, M., Cochrane, S., Hogg, M. A., \& Turner, J. C. (1990). Knowing what to think by knowing who you are: Self-categorisation and the nature of norm formation, conformity and group polarisation. British Journal of Social Psychology, 29, 97-119.

Allen, V. L. (1975). Social support for nonconformity. In L. Berkowitz (Ed.), Advances in experimental social psychology (Vol. 8, pp. 1-43). New York: Academic Press.

*Amir, T. (1984). The Asch conformity effect: A study in Kuwait. Social Behavior and Personality, 12, 187-190.

*Asch, S. E. (1951). Effects of group pressure on the modification and distortion of judgments. In H. Guetzkow (Ed.), Groups, leadership and men (pp. 177-190). Pittsburgh, PA: Carnegie Press.

*Asch, S. E. (1952a). Social psychology. Englewood Cliffs, NJ: Prentice-Hall.

Asch, S. E. (1952b). Effects of group pressure on the modification and distortion of judgments. In G. E. Swanson, T. M. Newcomb, \& E. L. Hartley (Eds.), Readings in social psychology (2nd. ed., pp. 2-11). New York: Holt.

Asch, S. E. (1955). Opinions and social pressure. Scientific American, 193, 33-35.

*Asch, S. E. (1956). Studies of independence and conformity. A minority of one against a unanimous majority. Psychological Monographs, 70 (9, Whole No. 416).

*Avramov-Kiwetz, M., \& Gaffié, B. (1974). Une approche expérimentale de l'immunité à l'influence sociale dans les petits groupes [An experimental approach to resistance to social 
influence in small groups]. Psychologie Française, 19, 23-40.

*Balance, W. G. (1968). Acquiescence: Acquiescent response style, social conformity, authoritarianism, and visual field dependency (Doctoral

dissertation, University of Alabama, 1967).

Dissertation Abstracts, 28B, 1165.

Baldwin, M. W., \& Holmes, J. G. (1987). Salient private audiences and awareness of the self. Journal of Personality and Social Psychology, 52, 1087-1098.

Baron, R. S., Vandello, J. A., \& Brunsman, B. (1996). The forgotten variable in conformity research: Impact of task importance on social influence. Journal of Personality and Social Psychology, 71, 915-927.

*Berkhouse, R. G. (1965). Effect of external reward on conformity and accuracy responses in a group pressure situation (Doctoral dissertation, The American University, 1965). Dissertation Abstracts, 26, 2332.

Bond, R., \& Smith, P. B. (1996). Culture and conformity: A meta-analysis of studies using Asch's (1952b, 1956) line judgement task. Psychological Bulletin, 119, 111-137.

*Brassard, L. G. (1986). The Asch conformity paradigm as a contrived in-vivo criterion for validating the College Self-Expression Scale of Assertion (Doctoral dissertation, University of Southern Mississipi, 1986). Dissertation Abstracts International, 47B, 4642.

Brehm, J. W. (1966). A theory of psychological reactance. New York: Academic Press.

Campbell, J. D., \& Fairey, P. J. (1989). Informational and normative routes to conformity: The effect of faction size as a function of norm extremity and attention to the stimulus. Journal of Personality and Social Psychology, 57, 457-468.

Carver, C. S. (1979). A cybernetic model of self-attention processes. Journal of Personality and Social Psychology, 37, 1251-1281.

Carver, C. S., \& Scheier, M. F. (1981). Attention and self-regulation: A control-theory approach to human behavior. New York: Springer-Verlag.

*Chandra, S. (1973). The effects of group pressure in perception: A cross-cultural conformity study. International Journal of Psychology, 8, 37-39.

Chapko, M. K., \& Revers, P. (1976). Contagion in a crowd: The effects of crowd size, and initial discrepancy from unanimity. Journal of Personality and Social Psychology, 33, 382-386.

Chapko, M. K., \& Revers, P. (1978). Contagion in a crowd: Conditions under which a crowd will reverse itself. Journal of Social Psychology, 105, 313-314.
*Claeys, W. (1967). Conformity behavior and personality variables in Congolese students. International Journal of Psychology, 2, 13-23.

*Cohen, B. P. (1958). A probability model for conformity. Sociometry, 21, 69-81. [Also in Cohen, B. P. (1963). Conflict and conformity: A probability model and its application. Cambridge, MA: MIT Press.]

*Cohen, B. P., \& Lee, H. (1975). Conflict, conformity and social status. Amsterdam: Elsevier. [See also Lee, H. E. (1972). A Markov chain model for Asch-type conformity experiments. Journal of Mathematical Sociology, 2, 131-142.]

*Conger, T. W. (1973). The equivalence of group conformity measures: Fact or fiction (Doctoral dissertation, Florida State University, 1972). Dissertation Abstracts International, 33B, 2789.

*Costanzo, P. R. (1970). Conformity development as a function of self-blame. Journal of Personality and Social Psychology, 14, 366-374.

*Costanzo, P. R., \& Shaw, M. E. (1966). Conformity as a function of age level. Child Development, 37, 967-975.

Cowan, G., \& Hodge, C. (1996). Judgments of hate speech: The effects of target group, publicness, and behavioral responses of the target. Journal of Applied Social Psychology, 26, 355-374.

*Critchlow, K. F., Herrup, R., \& Dabbs, J. M. (1968). Experimenter influence in a conformity situation. Psychological Reports, 23, 408-410.

*Cull, J. (1971). Conformity behavior in schizophrenics. Journal of Social Psychology, 84, 45-49. [Also in Cull, J. (1976). The relationship between sex role and modification of judgments. Journal of Psychology, 93, 313-317.]

*Cull, J. G., \& Parker, L. E. (1973). Mental retardation and conformity behavior. Training School Bulletin, 69, 168-173.

*Deutsch, M., \& Gerard, H. B. (1955). A study of normative and informational influences upon individual judgment. Journal of Abnormal and Social Psychology, 51, 629-636. [See also Gerard, H. B. (1964). Conformity and commitment to the group. Journal of Abnormal and Social Psychology, 68, 209-211.]

*Doms, M., \& van Avermaet, E. (1980). Majority influence, minority influence and conversion behavior: A replication. Journal of Experimental Social Psychology, 16, 283-292.

*Doms, M., \& van Avermaet, E. (1985). Social support and minority influence: The innovation effect reconsidered. In S. Moscovici, G. Mugny, \& E. van Avermaet (Eds.), Perspectives on minority influence (pp. 53-74). Cambridge, UK: Cambridge University Press. 
Eagly, A. H., \& Carli, L. L. (1981). Sex of researchers and sex-typed communications as determinants of sex differences in influenceability: A meta-analysis of social influence studies. Psychological Bulletin, 90, 1-20.

*Feldman, M. J., \& Goldfried, M. R. (1962). Validity of group judgment as a factor affecting independent and conformity behavior. Journal of Social Psychology, 58, 289-294.

*Frager, R. (1970). Conformity and anti-conformity in Japan. Journal of Personality and Social Psychology, 15, 203-210.

*Gerard, H. B., \& Rotter, G. S. (1961). Time perspective, consistency of attitude, and social influence. Journal of Abnormal Social Psychology, 62, 565-572.

*Gerard, H. B., Wilhelmy, R. A., \& Conolley, E. S. (1968). Conformity and group size. Journal of Personality and Social Psychology, 8, 79-82.

Goldberg, S. C. (1954). Three situational determinants of conformity to social norms. Journal of Abnormal and Social Psychology, 49, 325-329.

*Gorfein, D. (1961). Conformity behavior and the 'authoritarian personality'. Journal of Social Psychology, 53, 121-125.

*Gorfein, D., Kindrick, T., Leland, Q., McAvoy, M. E., \& Barrows, J. (1960). Cognitive dissonance and yielding behavior. Journal of Psychology, 50, 205-208.

*Gould, L. J. (1969). Conformity and marginality: Two faces of alienation. Journal of Social Issues, 25, 39-63.

*Hatcher, J. (1982). Arousal and conformity. In H. Brandstatter, J. H. Davis, \& G. StockerKreichgauer (Eds.), Group decision-making (pp. 453-472). London: Academic Press.

Hedges, L. V., \& Olkin, I. (1985). Statistical methods for meta-analysis. San Diego, CA: Academic Press.

*Hornik, J. A. (1974). Conformity, consistency and commitment: An investigation of a formal theoretical model of decision-making processes in social situations (Doctoral dissertation, University of Illinois, 1971). Dissertation Abstracts International, $34 B, 854$.

*Horowitz, I. A., \& Rothschild, B. H. (1970). Conformity as a function of deception and role playing. Journal of Personality and Social Psychology, 14, 224-226.

Insko, C. A., Smith, R. H., Alicke, M. D., Wade, J., \& Taylor, S. (1985). Conformity and group size: The concern with being right and the concern with being liked. Personality and Social Psychology Bulletin, $11,41-50$.
*Kagan, J., \& Mussen, P. H. (1956). Dependency themes on the TAT and group conformity. Journal of Consulting Psychology, 20, 29-32. [Also in Mussen, P. H., \& Kagan, J. (1958). Group conformity and perceptions of parents. Child Development, 29, 57-60.]

*Kidd, A. H., \& Karpan, M. M. (1967). Responses of prisoners to social pressure. Psychological Reports, 20, 47-49.

Kidd, J. S. (1956). Social influence phenomena in a task-oriented group situation. Journal of Abnormal and Social Psychology, 56, 13-17.

Kumar, J. (1983). Conformity behavior as a function of confederates' age and size of the confederate group. Personality Study and Group Behaviour, 3, 69-73.

*Lamb, T. A., \& Alsifaki, M. (1980). Conformity in the Asch experiment: Inner-other directedness and the defiant subject. Social Behaviour and Personality, 8, 13-16.

Lambert, A. J., Cronen, S., Chasteen, A. L., \& Lickel, B. (1996). Private vs. public expressions of racial prejudice. Journal of Experimental Social Psychology, 32, 437-459.

*Larsen, K. S. (1974). Conformity in the Asch experiment. Journal of Social Psychology, 94, 303-304.

*Larsen, K. S. (1990). The Asch conformity experiment: Replication and transhistorical comparisons. Journal of Social Behavior and Personality, 5, 163-168.

*Larsen, K. S., Triplett, J. S., Brant, W. D., \& Langenberg, D. (1979). Collaborator status, subject characteristics and conformity in the Asch paradigm. Journal of Social Psychology, 108, 259-263.

Latané, B. (1981). Psychology of social impact. American Psychologist, 36, 343-356.

Latané, B., \& Wolf, S. (1981). The social impact of majorities and minorities. Psychological Review, 88, 438-453.

Lavine, H., \& Snyder, M. (1996). Cognitive processing and the functional matching effect in persuasion: The mediating role of subjective perceptions of message quality. Journal of Experimental Social Psychology, 32, 580-604.

*Levy, L. (1960). Studies in conformity. Journal of Psychology, 50, 39-41.

*Liberman, D., \& Meyerhoff, M. K. (1986). Differential conformity rates to perceptual and logical tasks. Journal of Social Psychology, 126, 273-275.

*Linde, T. F., \& Patterson, C. H. (1964). Influence of orthopedic disability on conformity behavior. Journal of Abnormal and Social Psychology, 68, 115-118. 
*Long, H. B. (1967). Relationships between conforming judgment and employee rank and between conforming judgment and dogmatism in an employee group (Doctoral dissertation, Florida State University, 1966). Dissertation Abstracts, 27A, 2616.

*Long, H. B. (1970). Relationships of selected personal and social variables in conforming judgment. Journal of Social Psychology, 81, 177-182.

*Long, H. B. (1972). Differences between content conformity and visual conformity. Adult Education, 22, 282-290.

Mackie, D. M. (1987). Systematic and nonsystematic processing of majority and minority persuasive communications. Journal of Personality and Social Psychology, 53, 41-52.

Mann, L. (1977). The effect of stimulus queues on queue-joining behavior. Journal of Personality and Social Psychology, 35, 437-442.

*Marsella, A. J. (1969). Conformity and psychopathology (Doctoral dissertation, Pennsylvania State University, 1968). Dissertation Abstracts, 29B, 3917.

*McKissack, I. J. (1971). Conformity in Ghana. British Journal of Social and Clinical Psychology, 10, 87.

Milgram, S., Bickman, L., \& Berkowitz, L. (1969). Note on the drawing power of crowds of different size. Journal of Personality and Social Psychology, 13, 79-82.

*Moeller, G., \& Applezweig, M. H. (1957). A motivational factor in conformity. Journal of Abnormal and Social Psychology, 55, 114-120. [Also reported in Appley, M. H., \& Moeller, G. (1963). Conforming behavior and personality variables in college women. Journal of Abnormal and Social Psychology, 66, 284-290.]

Moscovici, S. (1980). Towards a theory of conversion behavior. In L. Berkowitz (Ed.), Advances in experimental social psychology (Vol. 13, pp. 209-239). New York: Academic Press.

Mullen, B. (1983). Operationalizing the effect of the group on the individual: A self-attention perspective. Journal of Experimental Social Psychology, 19, 295-322.

Mullen, B. (1987). Self-attention theory: The effects of group composition on the individual. In B. Mullen \& G. R. Goethals (Eds.), Theories of group behavior (pp. 125-146). New York: Springer-Verlag.

Nemeth, C., Wachtler, J., \& Endicott, J. (1977). Increasing the size of the minority: Some gains and some losses. European Journal of Social Psychology, 7, 15-27.

*Neto, F. (1994). Conformity and independence revisited.
Unpublished manuscript, University of Oporto, Portugal.

*Nicholson, N., Cole, S. G., \& Rocklin, T. (1985). Conformity in the Asch situation: A comparison between contemporary British and US university students. British Journal of Social Psychology, 24, 59-63.

*Nikols, S. A. (1965). A study of the additivity of variables influencing conformity (Doctoral dissertation, University of Florida, 1964).

Dissertation Abstracts, 25, 6095.

Nordholm, L. A. (1975). Effects of group size and stimulus ambiguity on conformity. Journal of Social Psychology, 97, 123-130.

*Perrin, S., \& Spencer, C. P. (1981). Independence or conformity in the Asch experiment as a reflection of cultural and situational factors. British Journal of Social Psychology, 20, 205-210.

*Pollis, N. P., \& Cammalleri, J. A. (1968). Social conditions and differential resistance to majority pressure. Journal of Psychology, 70, 69-76.

Reitan, H. T. (1969). Conformity, majority effect and perceived competence (Doctoral dissertation, University of Florida, 1967). Dissertation Abstracts International, 29B, 1163.

*Reitan, H. T., \& Shaw, M. E. (1964). Group membership, sex-composition of the group, and conformity behavior. Journal of Social Psychology, 64, 45-51.

*Rodrigues, A. (1982). Replication: A neglected type of research in social psychology. Interamerican Journal of Psychology, 16, 91-109.

Rosenberg, L. A. (1961). Group size, prior experience, and conformity. Journal of Abnormal and Social Psychology, 63, 436-437.

* Rotter, G. S. (1967). An experimental evaluation of group attractiveness as a determinant of conformity. Human Relations, 20, 273-281.

* Ryan, J. H. (1983). The relationship between ego identity status, conformity behavior, and personality in college students (Doctoral dissertation, Utah State University, 1982). Dissertation Abstracts International, 44B, 3541.

*Schulman, G. I. (1967). Asch conformity studies: Conformity to the experimenter and/or to the group? Sociometry, 30, 26-40.

*Schuman, H. M. (1970). Social conformity and relative prestige (Doctoral dissertation, Claremont Graduate School and University Center, 1968). Dissertation Abstracts, 30B, 374.

Schwartz, S. H. (1994) Cultural dimensions of values: Towards an understanding of national differences. In U. Kim, H. C. Triandis, C. Kagitcibasi, S. C. Choi, \& G. Yoon (Eds.), 
Individualism and Collectivism: Theory, method and applications (pp. 85-119). Thousand Oaks, CA: Sage.

*Seaborne, A. E. M. (1962). Group influence on the perception of ambiguous stimuli. British Journal of Social Psychology, 53, 287-298.

*Stamps, L. W., \& Teevan, R. C. (1974). Fear of failure and conformity in the Asch and Crutchfield situations. Psychological Reports, 34, 1327-1330.

Stang, D. J. (1976). Group size effects on conformity. Journal of Social Psychology, 98, 175-181.

Stasser, G., \& Davis, J. H. (1981). Group decision making and social influence: A social interaction sequence model. Psychological Review, 88, 523-551.

Tajfel, H. (1981). Human groups and social categories: Studies in social psychology. Cambridge, UK: Cambridge University Press.

Tajfel, H. (1982). Social psychology of intergroup relations. Annual Review of Psychology, 33, 1-39.

Tanford, S., \& Penrod, S. (1984). Social influence model: A formal integration of research on majority and minority influence processes. Psychological Bulletin, 95, 189-225.

*Timaeus, E. (1968). Untersuchungen zum sogennanten konformen Verhalten [Studies on conformity behavior]. Zeitschrift für Experimentelle und Angewandte Psychologie, 15, 176-194.

*Toder, N. L., \& Marcia, J. E. (1973). Ego identity status and response to conformity pressure in college women. Journal of Personality and Social Psychology, 26, 287-294.

Turner, J. C. (1991). Social influence. Milton Keynes, UK: Open University Press.

*Vlaander, G., \& van Rooijen, L. (1985).
Independence and conformity in Holland: Asch's experiment in Holland three decades later. Gedrag, 13, 49-55.

*Wagner, P. J., \& Shaw, M. E. (1973). Effects of the subject's awareness of the nature of the experiment upon conformity behavior. Bulletin of the Psychonomic Society, 1, 235-237.

*Whittaker, J. O., \& Meade, R. D. (1967). Social pressure in the modification and distortion of judgment: A cross-cultural study. International Journal of Psychology, 2, 109-113.

*Whittaker, J. O., Rosenau, C. D., Farnsworth, H., \& Grosz, R. (1957). A repetition of Asch's effects of group pressure on modification and distortion of judgments. Perceptual and Motor Skills, 7, 245.

Wilder, D. A. (1977). Perception of groups, size of opposition, and social influence. Journal of Experimental Social Psychology, 13, 253-268.

*Williams, T. P., \& Sogon, S. (1984). Group composition and conforming behavior in Japanese students. Japanese Psychological Research, 26, 231-234.

Paper received 11 April 2003; revised version accepted 13 September 2004.

\section{Biographical note}

ROD BOND is a member of the Social and Health Psychology research group in the Department of Psychology, University of Sussex, UK. His research interests are in the areas of social influence, intra-group processes and multivariate statistical methods. 